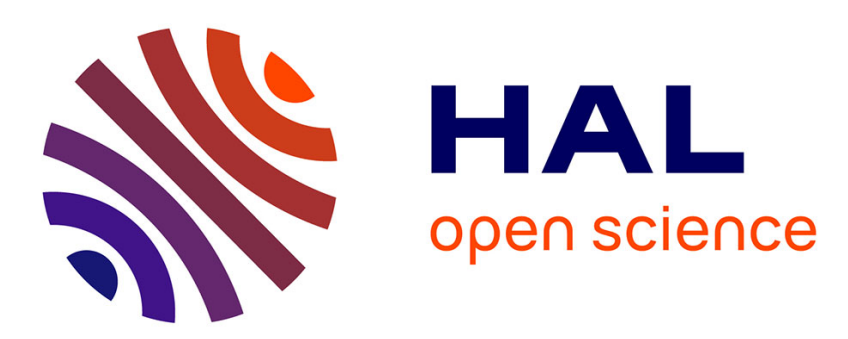

\title{
Information processing during physical exercise: a chronometric and electromyographic study
}

Karen Davranche, Boris Burle, Michel Audiffren, Thierry Hasbroucq

\section{To cite this version:}

Karen Davranche, Boris Burle, Michel Audiffren, Thierry Hasbroucq. Information processing during physical exercise: a chronometric and electromyographic study. Experimental Brain Research, 2005, 165 (4), pp.532-540. 10.1007/s00221-005-2331-9 . hal-02096523

\section{HAL Id: hal-02096523 \\ https://hal.science/hal-02096523}

Submitted on 11 Apr 2019

HAL is a multi-disciplinary open access archive for the deposit and dissemination of scientific research documents, whether they are published or not. The documents may come from teaching and research institutions in France or abroad, or from public or private research centers.
L'archive ouverte pluridisciplinaire HAL, est destinée au dépôt et à la diffusion de documents scientifiques de niveau recherche, publiés ou non, émanant des établissements d'enseignement et de recherche français ou étrangers, des laboratoires publics ou privés. 


\section{Karen Davranche $\cdot$ Borís Burle $\cdot$ Michel Audiffren \\ Thierry Hasbroucq \\ Information processing during physical exercise: a chronometric and electromyographic study}

Received: 19 October 2004 / Accepted: 23 February 2005 / Published online: 10 May 2005

(C) Springer-Verlag 2005

\begin{abstract}
Choice reaction time (RT) is shorter when participants perform a choice task at the same time as a sub-maximal exercise than when they are at rest. The purpose of the present study was to determine whether such an exercise affects response execution or whether it alters processes located upstream from the neuro-muscular level. To this end, the electromyographic (EMG) activity of the response agonists was analysed in a between-hand choice RT task performed either concurrently with a pedalling task or at rest. Visual stimulus intensity was also manipulated so as to determine whether exercise further affects early sensory processes. Results shows that exercise affected the time interval elapsing from the onset of the contraction of the response agonists to the mechanical response, thereby indicating that this variable modifies the peripheral motor processes involved in response execution. EMG signal analyses further revealed that the cortico-spinal command is more efficient during exercise than at rest. In addition, exercise was shown to interact with visual stimulus intensity on the time between stimulus and voluntary EMG onset and to increase the critical flicker fusion frequency threshold, thereby indicating that exercise modifies the peripheral sensory processes involved in early sensory operations. The decomposition of RT, with respect to the EMG activity of response agonists, sheds light on the processes affected by exercise and suggests that exercise affects both sensory processes and late motor processes.
\end{abstract}

K. Davranche $(\varangle) \cdot$ M. Audiffren

Laboratoire d'Analyse de la Performance Motrice Humaine, Maison des Sciences de l'Homme et de la Société,

99 Avenue du Recteur Pineau, 86000 Poitiers, France

E-mail: karen.davranche@up.univ-mrs.fr

Tel.: + 33-491-164332

Fax: $+33-491-774969$

K. Davranche $\cdot$ B. Burle $\cdot$ T. Hasbroucq Laboratoire de Neurobiologie de la Cognition, Centre National de la Recherche Scientifique and Université de Provence, 31 Chemin Joseph-Aiguier, 13402 Marseille cedex 20, France
Keywords Fractionated RT · Motor time ·

Distributional analysis - Additive factor method .

Stimulus intensity $\cdot$ Critical flicker fusion frequency threshold

\section{Introduction}

Despite the fact that results are not unequivocal, several studies suggest that choice reaction time (RT) is shorter when participants perform a choice task simultaneously with a sub-maximal exercise than when they are at rest (for reviews see McMorris and Graydon 2000; Tomporowski 2003). The beneficial effect of physical exercise, however, remains poorly understood. The aim of the present study was to shed light on this issue.

Most authors agree that choice RT can be decomposed into a series of stages (Anderson 1980), a stage being a functional set of elementary operations. Van der Molen et al (1991), for instance, proposed a six-stage breakdown of information processing: three perceptual stages (stimulus preprocessing, feature analysis, and stimulus identification); a central stage (response selection); and two motor stages (motor programming and motor adjustment).

The question of which stages are affected by physical exercise has so far been addressed using the additive factor method (AFM; Sternberg 1969, 2001). This inferential method relies upon analysing the pattern of statistical effects of factorially manipulated variables. If the effects on RT are additive, it is likely that the variables affect different stages; conversely, if the effects interact, it is likely that the variables affect at least one common stage. These simple inference rules hold for most serial and parallel information processing models (see Miller et al 1995). Using this logic, Arcelin et al (1998) and Davranche and Audiffren (2004) have found that the effect of physical exercise is additive with the effects of signal quality, stimulus-response 
compatibility and foreperiod duration, which suggests that physical exercise spares the stages of stimulus identification, response selection, and motor adjustment.

The locus of the effect of an experimental manipulation can also be addressed by fractioning the RT with respect to a change in electrophysiological activity (Hasbroucq et al 2002). The electromyographic (EMG) activity of the response agonists allows such a fractioning (Botwinick and Thompson 1966). The time interval between the onset of the response signal and the onset of EMG activity is termed premotor time (PMT), while the time interval between the onset of EMG activity and the onset of the required motor response is termed motor time (MT). MT reflects the duration of the actual execution of the response, which constitutes the neuro-muscular component of the motor adjustment stage, whereas PMT reflects the duration of all preceding processes. By examining the effect of an experimental manipulation on PMT and MT, it is possible to determine whether the manipulation's effects on RT occur after or before EMG onset and, therefore, whether it affects response execution and/or processes occurring upstream in the information flow (Botwinick and Thompson 1966; Hasbroucq et al 1995, 2001, 2003; Possamaï et al 2002; Rihet et al 1999). Furthermore, to better characterise the effect of a manipulated variable on motor execution processes, another index called the $\alpha$ angle can be analysed (Hasbroucq et al 1995; Possamaï et al 2002). The $\alpha$ angle is the angle between the baseline EMG activity and the maximum of the rectified EMG burst (Hasbroucq et al 1995). It is computed on a trial by trial basis and reflects the rate of recruitment of the motoneurons: the faster the rate of recruitment, the larger the $\alpha$ angle (Possamaï et al 2002). More precisely, and according to models of EMG and/or force production, the steepness of the EMG activity may be related to the variance of the motor unit onset time: the lower the variance (the more synchronized the motor unit discharges), the steeper the EMG activity (Meijers et al 1976; Ulrich and Wing 1991). In other words, the $\alpha$ angle likely reflects the quality of the cortico-spinal command.

The first aim of the present study was to decipher whether sub-maximal physical exercise affects response execution or whether it alters the processes located upstream from the neuro-muscular level. To this end, we recorded and analysed the EMG activity of the response agonists in a manual choice RT task performed either concurrently with a pedalling task, or at rest. If physical exercise has its locus prior to response execution, it should shorten the PMT and leave the MT unaffected. If, alternatively, exercise shortens response execution, it should affect the MT. In addition, in the latter case, the $\alpha$ angle analysis should provide a deeper understanding of the actual mechanism responsible for the effect of exercise. The prediction is that if exercise affects MT then the $\alpha$ angle should be larger during exercise than at rest.
A second aim of the present study was to investigate the effect of physical exercise on sensory processing. Several studies designed to assess the effects of exercise on tasks that measure perceptual and sensory processing failed to evidence systematic effects (for a review see Tomporowski 2003). To this end, the interaction between visual stimulus intensity and exercise was studied in order to determine whether these factors affect common sensory processes. Both neurophysiological and behavioural data indicate that visual signal intensity affects stimulus pre-processing. First, stimulus luminance affects the discharge latency of the ganglion cells of the retina (Lennie 1998). Second, several experiments suggest that the effect of this variable depends on retinal eccentricity but is unaffected by other variables known to alter the subject's performance (for reviews see Sanders 1990, 1998). Taken together, these findings support the notion that signal luminance specifically affects the stimulus pre-processing stage. Since factors affecting the same processes generally interact (Sternberg 1969, 2001), if physical exercise affects sensory processing, its effect on PMT was expected to depend on visual stimulus intensity. In addition, the critical flicker fusion frequency (CFF) test, which is considered to be a brief, objective, and quantitative index of cortical arousal and sensory sensitivity threshold, was also performed (Bobon et al 1982; Ghozlan and Wildlöcher 1993; Herskovic et al 1986).

\section{Method}

\section{Participants}

All participants, fully informed about the protocol, signed written consent forms. Participants were free of disease and not under medication. The subjects [six females and six males, aged $22-35(M=27$ years; $\mathrm{SD}=4)$ ] regularly practiced sports. The maximal oxygen uptake $\left(\mathrm{VO}_{2} \max : M=44 \mathrm{ml} \mathrm{kg}^{-1} \mathrm{~min}^{-1} ; \mathrm{SD}=8\right)$, the maximal aerobic power (MAP: $M=269 \mathrm{~W} ; \mathrm{SD}=64$ ), maximal heart rate (HRmax: $M=183$ beats $\min ^{-1} ; \mathrm{SD}=11$ ) and ventilatory threshold power (VTP: $M=142 \mathrm{~W} ; \mathrm{SD}=34$ ) were individually determined in a preliminary protocol. The subjects were included in the study if their power output reached at VTP was lower or equal to their power output reached at $50 \%$ of MAP. Participants' anthropometrical and physiological characteristics are presented in Table 1.

\section{Preliminary protocol}

The subjects performed an incremental cycling maximal test on an electrically braked stationary cycle ergometer (Ergoline 800S). After a 5-min warm-up at $25 \mathrm{~W}$, the workload increased by $25 \mathrm{~W}$ every minute until exhaustion. The pedalling rate was kept constant at $60 \mathrm{rpm}$. Participants were verbally encouraged to 
Table 1 Anthropometrical and physiological characteristics of subjects

\begin{tabular}{|c|c|c|}
\hline \multirow[t]{2}{*}{ Variable } & \multicolumn{2}{|c|}{ Mean \pm SD } \\
\hline & Female & Male \\
\hline Age (years) & $25 \pm 3$ & $28 \pm 4$ \\
\hline Height $(\mathrm{cm})$ & $168 \pm 8$ & $179 \pm 4$ \\
\hline Weight $(\mathrm{kg})$ & $59 \pm 7$ & $74 \pm 8$ \\
\hline $\mathrm{VO}_{2} \max \left(\mathrm{ml} \mathrm{min}{ }^{-1} \mathrm{~kg}^{-1}\right)$ & $38 \pm 5$ & $49 \pm 4$ \\
\hline $\mathrm{PVO}_{2} \operatorname{maxW}$ & $213 \pm 21$ & $329 \pm 30$ \\
\hline $\mathrm{HR}_{\max }\left(\mathrm{bmp} \min ^{-1}\right)$ & $181 \pm 11$ & $181 \pm 10$ \\
\hline $\mathrm{P}_{\mathrm{VT}}(\mathrm{W})$ & $113 \pm 14$ & $175 \pm 20$ \\
\hline
\end{tabular}

Note: $\dot{\mathrm{VO}}_{2}$ max maximal oxygen uptake; $\mathrm{PVO}_{2}$ max power at maximal oxygen uptake; $\mathrm{HR}_{\mathrm{MAX}}$, maximal heart rate; $\mathrm{P}_{\mathrm{VT}}$ power at ventilatory threshold

achieve their maximal level. The subject breathed through a facemask (Hans Rudolph). Expired gas flows were measured using a pneumotachograph (Type 3 Hans Rudolph) and analysed breath-by-breath using an automated system (Medi Soft, Exp'air 1.26). The metabolic and ventilatory parameters, including oxygen uptake $\left(\dot{\mathrm{VO}}_{2} \max \right)$ carbon dioxide production $\left(\dot{\mathrm{VCO}}_{2}\right)$ expiratory flow (VE) tidal volume (VT), respiratory rate (RR) and duty cycle (ratio between inspiratory time and total time of the cycle), were monitored continuously and averaged every $15 \mathrm{~s}$. A four-lead electrocardiogram recorded heart rate continuously. All participants achieved $\mathrm{VO}_{2}$ max as defined by the following criteria: (1) the subject was no longer able to cycle, despite encouragement; (2) a plateau in $\mathrm{VO}_{2}$ kinetic was observed despite an increase in workload; (3) the respiratory exchange ratio $\left(\mathrm{CO}_{2} / \mathrm{VO}_{2}\right)$ was greater than 1.15; and (4) the age predicted maximum HR was obtained.

Task

Subjects were seated on a cycle ergometer (Ergoline 800 S), the fronts arms posed on a foam rubber support. In front of the subject, a row of three light emitting diodes (LEDs) were positioned at a distance of $60 \mathrm{~cm}$. The height of the board was regulated in order to place the horizontal line formed by the diodes in the line of gaze. The green central LED (off) served as a fixation point and as a warning signal (on), the two red LEDs displayed the imperative stimuli. The outer LEDs were located at $7.5 \mathrm{~cm}$ on each side of the central one. The distance between the outer LEDs and the central one subtended $7^{\circ}$ of visual angle. Two response keys were fixed on the right and the left handles of the bicycle's handlebar. Subjects were asked to respond as quickly and accurately as possible to the visual stimuli by pressing the appropriate key with the thumb $(7.5 \mathrm{~N})$. The left key was to be pressed in response to the left stimulus and the right key in response to the right stimulus.

The experiment took place in a dimly lit room. A trial began with the central LED being lit $(50 \mathrm{~ms}) ; 500 \mathrm{~ms}$ later one of the two lateral LEDs was lit, either strongly $(0.8 \mathrm{mcd})$ or weakly $(0.2 \mathrm{mcd})$. Stimulus intensity was varied within blocks. The response extinguished the stimulus. The next trial started $200 \mathrm{~ms}$ after the response. If the response was not given within $1,500 \mathrm{~ms}$ after the stimulus, the trial was considered to be an omission. If the response was given less than $150 \mathrm{~ms}$ after the stimulus, the trial was considered to be an anticipation. In these cases, the stimulus was extinguished and a new trial began.

\section{Design}

Trials were presented in blocks of 68 . The first four trials were warm-up trials. Within a block, each stimulus (strong/left, strong/right, weak/left and weak/right) was presented equally often according to pseudo-random series.

During the session, each subject performed eight blocks of 68 trials. The first two blocks were practice blocks and were discarded. Thereafter, the subjects performed three consecutive blocks during exercise (while cycling at $50 \%$ of MAP) and three consecutive blocks at rest. The order of exercise and rest was counter-balanced across subjects. The three consecutive blocks (204 trials) lasted between 14 and $15 \mathrm{~min}$. A resting period (about $10 \mathrm{~min}$ ) was given to the subjects between the two conditions of exercise.

When subjects performed the task during exercise, the test started with a 5-min warm-up period (without performing the RT task) and pedal rate was freely chosen. Five minutes after the beginning of the cycling task, the simultaneous task began. Heart rate was continuously recorded during the simultaneous task with sport tester systems (Polar). No knowledge of results concerning heart rate, pedal rate, and RT performance was given to the subjects.

\section{Critical flicker fusion frequency}

The CFF measurements were carried out before and immediately after exercise. Participants were seated in front of a viewing chamber (Campden Instruments, 12021), constructed to control extraneous factors that might distort CFF values. The viewing chamber presented two light-emitting diodes $\left(58 \mathrm{~cd} / \mathrm{m}^{2}\right)$ simultaneously: one for the left eye and one for the right eye. The stimuli were separated by $2.75 \mathrm{~cm}$ (centre to centre) with a stimulus to eye distance of $15 \mathrm{~cm}$ and a viewing angle of $1.9^{\circ}$. The inside of the viewing chamber was painted flat black to minimise reflection. The flicker frequency increment $(1 \mathrm{~Hz} / \mathrm{s})$ changed in two different ways: either it increased (from $0 \mathrm{~Hz}$ to $100 \mathrm{~Hz}$ ) until the subject perceived fusion, or it decreased (from $100 \mathrm{~Hz}$ to $0 \mathrm{~Hz}$ ) until a flicker was detected. After a fovea binocular fixation, participants were required to respond by pressing a button when 
they identified the visual flicker (descending frequency) and the fusion (ascending frequency) thresholds. Six trials, three ascending and three descending, were performed alternatively. The average of the six values, representing the sensory sensitivity criterion, was calculated for each subject. Moreover, the ascending $(f a)$ and descending $(f d)$ threshold difference $(\Delta=f a-f d)$ was individually computed to assess the subjective judgment criterion.

\section{EMG recordings}

The EMG of the flexor pollicis brevis of each thumb was recorded by mean of paired surface $\mathrm{Ag}-\mathrm{AgCl}$ electrodes, $11 \mathrm{~mm}$ in diameter, fixed $2 \mathrm{~cm}$ apart on the skin of the thenar eminence. This activity was amplified (gain 10,000 ), filtered (low frequency cut-off $10 \mathrm{~Hz}$, high frequency cut-off $1 \mathrm{kHz}$ ) and digitised on-line $(2 \mathrm{kHz})$. The experimenter continuously monitored the EMG signal in order to avoid background activity as much as possible. If the signal became noisy, the experimenter asked the subject to relax his/her muscles.

\section{Signal processing}

The EMG traces were inspected off-line, trial by trial, as displayed on a computer screen. Since human pattern recognition processes are superior to automated algorithms (van Boxtel et al 1993), we hand-scored the EMG onsets. The trace corresponding to the EMG was displayed on the computer screen and the EMG onset was marked using the computer mouse. Importantly, at this stage the experimenter was unaware of the exercise condition and of the signal intensity condition he was looking at. The peaks of the EMG and the $\alpha$ angle were automatically determined by a computer program.

The signal, time-locked to the change in EMG activity, was averaged for each subject in the rest and exercise conditions, separately. The surface under the curves was calculated in a $40 \mathrm{~ms}$ time window starting from the change in activity. This time window was the same for all the subjects and was determined in terms of the grand average of the EMG activity. This corresponded to the time elapsed between the change in activity and the peak of the averaged EMG bursts.

\section{Trial selection}

After visual inspection, 427 trials, which represented $9.3 \%$ of the total number of trials, were discarded from the analysis. $3.8 \%$ of the correct trials were also rejected because of tonic activity or artefacts. In addition, 5.5\% of the correct trials were discarded because of dualactivation trials, with an activation preceding the correct one (Burle et al 2002; Hasbroucq et al 1999).

\section{Data analyses}

The overall RT, $\alpha$ angle, surface under the curve and arcsine transforms of the error rate were submitted to repeated measures analyses of variance (ANOVAs) with exercise conditions and visual stimulus intensity as within-subject factors.

The effect of exercise on fractionated RT was assessed using a repeated-measures multivariate analysis of variance (MANOVA), with PMT and MT as the dependent variables and with exercise conditions (exercise vs rest) and visual stimulus intensity as withinsubject factors. Follow-up separate repeated-measures ANOVAs were carried out on each of the dependent variables. Effects sizes in the MANOVA and in the ANOVAs were estimated by calculating the eta squared $\left(\eta_{2}\right)$, and effect sizes for the post hoc analyses were estimated using Cohen's $d$.

In addition, distribution analyses were performed on PMT and MT data, in order to explore the cognitive performance at a more fine-grained level and to obtain more information than can be achieved using standard statistical summary measures like mean and variance. This technique aims to assess and characterise the effects of exercise on whole RT-distribution. To this aim, the "Vincent averaging" or "Vincentization" technique was used (Jianq et al 2004; Ratcliff 1979; Vincent 1912). The distributions were binned in ten classes and the mean of each bin was computed. This was done for each subject separately. Graphic representations of the distributions were constructed using group RT distributions obtained by averaging individual RT distributions. From the Vincentized distributions, delta plots were estimated by plotting the difference between the values of the same bins of the rest and exercise conditions against the average of the same two values. Repeated-measures ANOVAs involving exercise, visual intensity and deciles as within-subject factors were performed on PMT and MT distributions. For univariate repeated-measures ANOVA tests involving more than one degree of freedom, the Greenhouse-Geisser correction was conducted. In this case, the uncorrected degrees of freedom, the corrected $P$ value, and the epsilon value are reported. Post hoc analyses were conducted using the Newman-Keuls test on all significant interaction findings. Alpha was set at 0.05 .

\section{Results}

\section{Error rate}

The mean error rate was $0.13 \%$. The effect of exercise and visual stimulus intensity did not reach significant levels, neither as main effects (exercise: $F_{(1,11)}=3.14$, $P=0.10, \eta_{2}=0.08$; visual stimulus intensity: $\left.F<1\right)$, nor as component terms in their interaction $(F<1)$. Erroneous trials were excluded from further analyses. 


\section{Overall reaction time}

As we might expect, RT was faster in the exercise condition $(262 \mathrm{~ms})$ than in the rest condition $(275 \mathrm{~ms})^{1}$ $\left(F_{(1,11)}=12.85, P=0.004, \eta_{2}=0.13\right)$. The effect of signal intensity was significant both as a main effect $\left(F_{(1,11)}=276.54, P=0.001, \eta_{2}=0.7\right)$, and as a component term in the interaction with the effect of exercise $\left(F_{(1,11)}=7.73, p=0.018, \eta_{2}=0.01\right)$. The effects resulting from the manipulation of exercise differed from one signal intensity condition to the other. Newman-Keuls revealed a significant difference between rest and exercise in the strong signal intensity $(P=0.001, d=0.82)$ and in the weak signal intensity conditions $(P=0.001$, $d=0.37$ ). In addition, a significant difference was observed between weak and strong signal intensity at rest $(P=0.001, d=1.21)$ and during exercise $(P=0.001$, $d=1.49$; Table 2). Therefore, the effect of exercise was greater in the strong signal intensity condition than in the weak signal intensity condition.

Fractioning of reaction time and distributional analysis

The MANOVA indicated a significant effect for exercise condition $\left(F_{(1,11)}=12.93, P=0.004, \eta_{2}=0.003\right)$. Results from the separate ANOVAs performed on each of the dependent variables showed that both PMT and MT contributed to the improvement of RT performance (Table 2). The analysis performed on mean PMT revealed a main effect of signal intensity $\left(F_{(1,11)}=296.81\right.$, $p<0.001, \eta_{2}=0.86$ ), but no main effect of exercise $\left(F_{(1,11)}=0.4, P=0.54, \eta_{2}=0.003\right)$. These two factors, however, interacted $\left(F_{(1,11)}=14.70, P=0.003, \eta_{2}=0.01\right)$. Newman-Keuls analysis revealed that the effect of exercise on mean PMT was significant only in the strong signal intensity condition $(P=0.003, d=0.26)$. The ANOVA performed on mean MT revealed a main effect of exercise; MT was faster in the exercise than in the rest condition $\left(F_{(1,11)}=6.43, P=0.03, \eta_{2}=0.36\right)$. There was no effect of signal intensity manipulation on this variable $(F<1)$ and there was no sign of any interaction between these two factors $\left(F_{(1,11)}=1.18, P=0.30, \eta_{2}=0.001\right)$.

The PMT and MT cumulative density functions obtained at rest and during exercise are presented in Fig. 1. The distribution analyses showed a classical effect of deciles on both PMT and MT distributions. More importantly, an effect of exercise was only observed for the MT distribution $\left(F_{(1,11)}=6.28, P=0.03, \eta_{2}=0.8\right)$. There was no sign of any effect of exercise on PMT $(F<1)$ and no interaction between exercise and deciles on any chronometric variable (PMT: $F_{(9,99)}=1.24$, $\left.P=0.28, \eta_{2}=0.001 ; \mathrm{MT}: F<1\right)$. A repeated-measures ANOVA, involving exercise and decile as within-subject

\footnotetext{
${ }^{1}$ The relatively short reaction time observed in this study is probably due to the use of a very simple RT task, a compatible mapping and a constant foreperiod duration.
}

Table 2 Mean and standard deviations (SD) of overall reaction time, pre-motor time and motor time (ms) at rest and during exercise in the weak and strong signal intensity conditions

\begin{tabular}{lllll}
\hline Variable & \multicolumn{3}{l}{ Mean \pm SD } \\
\cline { 2 - 5 } & Rest & & Exercise \\
\hline Signal intensity & Weak & Strong & Weak & Strong \\
Reaction time & $288 \pm 23$ & $262 \pm 20$ & $279 \pm 25$ & $246 \pm 19$ \\
Pre-motor time & $199 \pm 19$ & $173 \pm 18$ & $200 \pm 23$ & $168 \pm 20$ \\
Motor time & $89 \pm 20$ & $89 \pm 19$ & $78 \pm 18$ & $78 \pm 17$ \\
\hline
\end{tabular}

factors, was performed on PMT recorded during the strong signal condition in order to clarify the interaction previously reported between exercise and signal intensity on PMT. The analysis revealed a main effect of deciles $\left(F_{(9,99)}=233.17, P<0.001\right.$; epsilon $\left.=0.16, \eta_{2}=0.91\right)$, and an interaction between exercise and deciles $\left(F_{(9,99)}=2.03, \quad P=0.04, \quad \eta_{2}=0.001\right) . \quad$ Newman-Keuls analysis revealed that exercise shortened the PMT of the first deciles (first decile $=8 \mathrm{~ms}, P<0.001, d=0.46$; second decile $=5 \mathrm{~ms}, \quad P=0.002, \quad d=0.32$; third decile $=5 \mathrm{~ms}, \quad P=0.004, \quad d=0.30 ;$ fourth decile $=4 \mathrm{~ms}$, $P=0.03, d=0.20$; fifth decile $=3 \mathrm{~ms}, P=0.08, d=0.16$; sixth decile $=5 \mathrm{~ms}, P=0.008, d=0.24$; seventh decile $=6 \mathrm{~ms}, \quad P=0.002, \quad d=0.28 ; \quad$ eighth decile $=4 \mathrm{~ms}$, $P=0.02, d=0.18$; ninth decile $=3 \mathrm{~ms}, P=.07, d=0.14)$, whereas the difference was not significant for the last decile (tenth decile $=2 \mathrm{~ms}, P=0.32, d=0.05$ ). The results are illustrated in Fig. 2.

\section{EMG activity}

The ANOVA performed on the $\alpha$ angle showed that this index was larger during exercise than at rest $\left(F_{(1,11)}=14.35, p<0.05, \eta_{2}=0.55 ; M=46^{\circ}, \mathrm{SD}=15\right.$ vs $\left.M=37^{\circ}, \mathrm{SD}=17\right){ }^{2}$ No effect of signal intensity was observed on this dependent variable $\left(F_{(1,11)}=1.63\right.$, $\left.P=0.23, \eta_{2}=0.002\right)$ and there was no sign of any interaction $(F<1)$. In addition, the surface under the averaged curve was larger during exercise than at rest $\left(F_{(1,11)}=8.27, P=0.02, \eta_{2}=0.41\right)$. No effect of signal intensity was observed on this index and there was no sign of any interaction $(F$ values $<1)$. The results are illustrated in Fig. 3.

\section{Critical flicker fusion frequency}

Regarding CFF data analyses, the data of one subject were lost because of data acquisition failure, and so the number of subjects was reduced to 11 . For the average

\footnotetext{
${ }^{2}$ The $\alpha$ angle is expressed in arbitrary units. Indeed, the value of this angle depends on the scale used for the $x$-axis (time) and the $y$-axis (voltage). Therefore, although this index reflects the rate of recruitment of the motoneurons as discussed by Hasbroucq et al (1995), its actual value is meaningless.
} 
Fig. 1 Cumulative density functions and delta plots (inset) of premotor time (PMT, left) and motor time (MT, right) during rest (thin lines) and exercise (thick lines). The effect of exercise only appears on the MT distribution and is consistent across all deciles
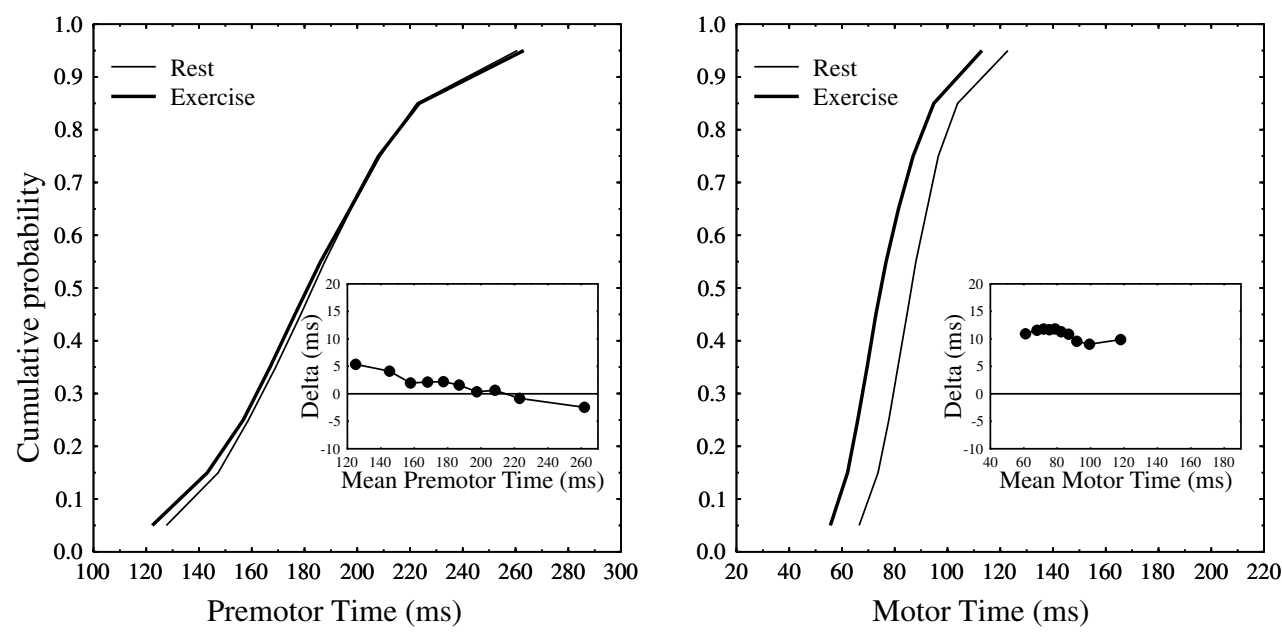

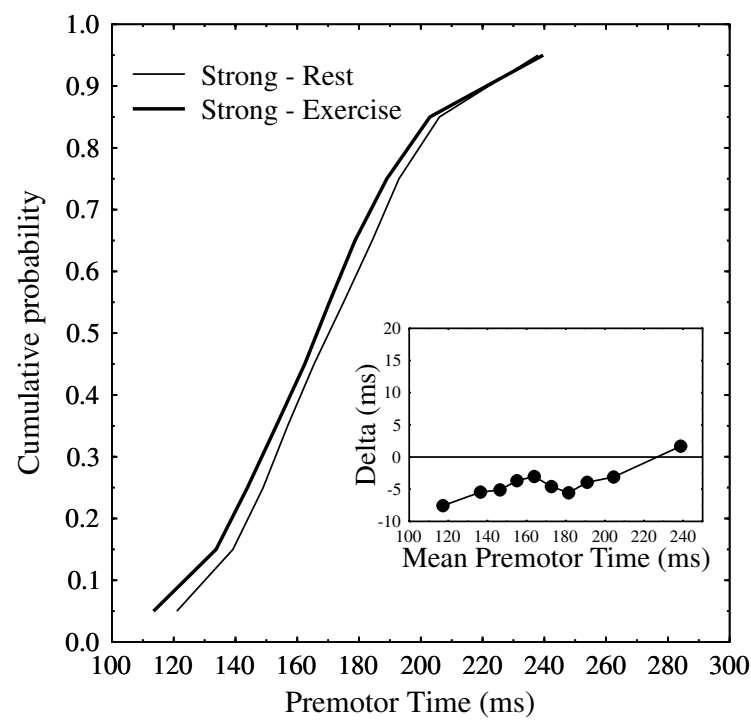

Fig. 2 Cumulative density functions and delta plots (inset) of premotor time (PMT) in the strong signal condition during rest (thin line) and exercise (thick line). Exercise shortens the PMT of the first deciles; however, the effect of exercise was not significant for the last decile (note that the effect was only marginal on the fifth and ninth deciles)

of the six values, representing the sensory sensitivity criterion, a main effect of exercise was observed on the CFF threshold $\left(F_{(1,10)}=5.62, P=0.04, d=0.36\right)$. After exercise, an increase of sensory sensitivity was seen (from $33.01 \mathrm{~Hz}, \mathrm{SD}=4$ to $34.45 \mathrm{~Hz}, \mathrm{SD}=4$ ). However, no significant effect of exercise was observed on the ascending and descending threshold difference $(\Delta=f a-$ $f d$ ), representing the subjective judgment criterion used by the subject (conservative or liberal) $(F<1)$.

\section{Discussion}

The present study confirms that choice RT performance is better when the task is performed simultaneously with

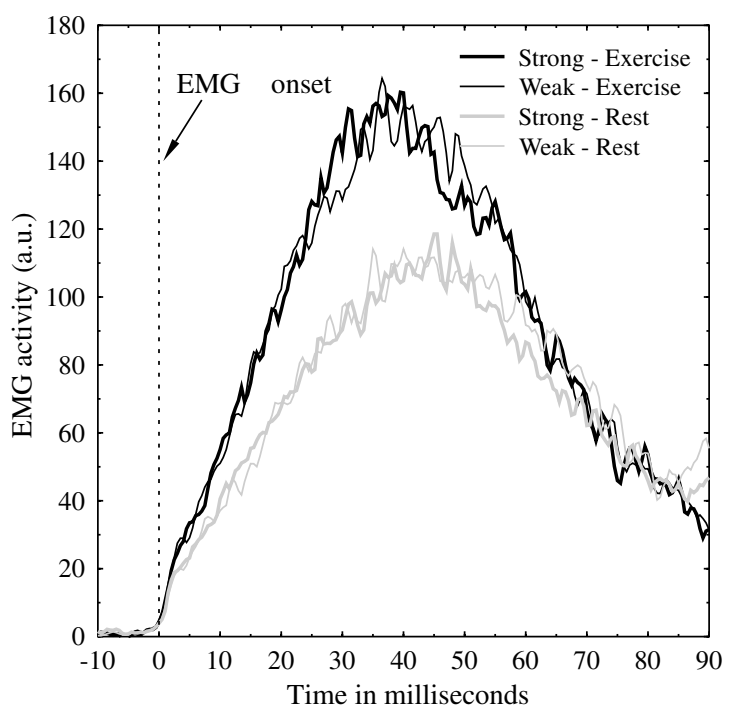

Fig. 3 Grand average of electromyographic (EMG) activity for the strong (thick lines) and weak (thin lines) visual intensity conditions during exercise (black lines) and rest (grey lines). The origin of the abscissa is set at the onset of the EMG activity (time 0)

a sub-maximal exercise (50\% of MAP) than when it is performed at rest. The fractioning of RT into PMT and MT with respect to the onset of EMG activity of the response agonists sheds light on the processes affected by exercise. Indeed, our results show that exercise affects MT but exerts little influence on PMT. ${ }^{3}$

Distribution analyses reveal that this effect is consistent across all MT deciles and therefore that is not due to extreme values. It is worth noting that the PMT distributions at rest and during exercise are almost perfectly superimposed. One must recall, however, that exercise and signal intensity interacted on mean PMT, suggesting

${ }^{3}$ The effect of the order factor on PMT and MT was analysed using a $2 \times 2 \times 3$ (Order factor $\times$ Exercise $\times$ Intensity) ANOVA. The greater $F$ obtained was $F_{(1,10)}=1.27, P=0.29$. Thus, the differences observed on PMT and on MT are not explained by possible carryover effects of exercise to the non-exercise test condition. 
that exercise does exert an effect, although complex, on this dependent variable. Distribution analysis and CFF threshold increase observed immediately after exercise confirm the improvement of sensory sensibility induced by exercise. However, the interaction between exercise and signal intensity is under-additive: the combined effect resulting from the manipulation of the two factors is lower than the sum of the separate effects of the two factors. Such a pattern may reveal that each component term of the interaction affects a different process among a set of processes operating in parallel within the same stage (Sternberg 1969). Now, visual stimulus intensity affects the discharge of the ganglion cells of the retina (Lennie 1998) and these cells receive convergent inputs from retinal receptors operating in parallel. It is therefore possible that physical exercise and visual intensity have differential effects on the retinal receptors. This interpretation, however, is speculative and should await further investigations.

The PMT and MT analyses suggest that sub-maximal exercise affects response execution and thus the neuromuscular component of the motor adjustment stage. This conclusion is strengthened by an analysis of the EMG activity of the response agonists. According to models of EMG and/or force production, the steepness of the EMG activity may be related to the variance of the motor unit onset time: the lower the variance, the more synchronized the motor unit discharges, and the steeper the EMG activity (Meijers et al 1976; Ulrich and Wing 1991). In other words, the cortico-spinal command was more efficient during exercise than at rest, which accounts for the effect of exercise on the MT. Note that modifications of the presynaptic inhibition of the Ia afferents to the motoneurons, reported during acute exercise and resulting in variations in the amplitude of the Hoffmann reflex (Motl and Dishman 2004; Motl et al 2003, 2004), cannot account for the present results. Indeed, while such modifications could possibly result in variations in MT, they cannot account for the differences in $\alpha$ angle demonstrated in the present study. Note also that according to Motl and Dishman (2003), the changes in presynaptic inhibition after cycling are restricted to the segments involved in the cycling task.

Further examination showed that the surface under the averaged curve during the interval separating the onset and the peak of the EMG activity burst was larger during exercise than at rest. Since the force generated by a muscle is monotonically related to this index (Bouisset and Matton 1995), the force produced during this time window was larger during exercise than at rest. Considered together, the results of the present study show that exercise has a motoric locus in the information processing chain. By the same token, it strengthens the results of the previous studies that attempted to localize the effect of exercise by using the AFM. In these studies, the effect of exercise was found to be additive on RT with the effects of stimulus discriminability and stimulus-response compatibility, two task factors chosen so as to affect stages preceding response execution, stimulus discriminability and stimulus-response compatibility, respectively. Arcelin et al (1998) reported an interaction between foreperiod duration and exercise on the last decile of the RT distribution. Since MT can be viewed as reflecting the neuromuscular component of motor adjustment, the stage affected by foreperiod duration, the whole pattern of results clearly converge in suggesting that physical exercise shortens RT by affecting peripheral motor processes.

With respect to the physiological mechanisms responsible for the effect of exercise, one possibility is that it is due to the elevation of body temperature which, in turn, would increase the conduction velocity of both muscle fibres and peripheral nerves (Van der Hoeven and Lange 1994). Although these results essentially concern the nerve and muscles involved in the performed exercise, there is evidence that the conduction velocity of the median nerve-which controls hand muscles - is increased during bicycling (Halar et al 1985). Note, however, that transcranial magnetic stimulation experiments suggest that exercise may also affect the excitability of the motor cortex (Samii et al 1996), which appears to favour an alteration of more central motor processes.

Moreover, other studies suggest that heat stress, exercise, and combinations of these stimuli induce a typical stress response, with secretion of catecholamines observed at both cortical and plasmatic levels (Brenner et al 1998; Harikai et al 2003). These results concur with studies suggesting that the effect of exercise on the motor processes may be mediated via the noradrenergic system. ${ }^{4}$ Indeed, Chmura et al $(1994,1998)$ have reported a negative correlation between plasma catecholamine concentration and RT during incremental exercise until exhaustion and after the plasmatic threshold of adrenalin is reached. In line with this view, Hasbroucq et al (2003) reported that a single dose of $50 \mathrm{mg}$ levodopa can shorten the MTs of healthy subjects. Like the effect of exercise in the present study, levodopa shortened MT throughout all of the deciles of the distribution. Now, levodopa is the precursor of both dopamine and noradrenaline. The results of Hasbroucq et al (2003) therefore suggest that catecholamines are involved in peripheral motor processes. In light of these results and those of Chmura et al $(1994,1998)$, the release of catecholamines during a sub-maximal exercise could be responsible for the present findings. However, without a plasma concentration sample, it is difficult to confirm that exercise induces significant increases in plasma catecholamine levels. Therefore, the involvement of catecholamine in the peripheral motor process changes observed in the present study should be interpreted with some caution. Future research should address this issue.

\footnotetext{
${ }^{4}$ Note, however, that other biochemical and hormonal changes resulting from the catecholamine concentration modification could be responsible for the cognitive performance improvement (McMorris et al 1999).
} 
Another aspect of the present results deserves some comment. Most of the effect of exercise was exerted on MT. Previous studies resorting to the same methodology have shown that some task variables, such as stimulusresponse compatibility, affect only the PMT, while other ones, such as response repertoire or foreperiod duration, affect both PMT and MT. To our knowledge, exercise is so far the only task variable which affects MT. This is an instance of a double dissociation, which suggests that the two variables are independent. Although relatively simple, the decomposition of RT with respect to the EMG activity of response agonists can provide useful information relative to the locus of RT effects and their functional mechanisms.

Acknowledgements The authors wish to thank Guy Reynard (CNRS, Marseille) and the Poitiers Regional University Hospital Center for their technical assistance, and Jacques LeHouezec (Pharmacia Upjohn) for providing the material for critical flicker fusion frequency. This work was supported by the French Ministry of Education, Research and Technology, MERT No. 61349220041.

\section{References}

Anderson JR (1980) Cognitive psychology and its implications. W.H. Freeman, San Francisco, CA

Arcelin R, Delignières D, Brisswalter J (1998) Selective effects of physical exercise on choice reaction processes. Percept Mot Skills 87:175-185

Bobon DP, Lecoq A, von Frenckell R, Mormont I, Lavergne G, Lottin $T$ (1982) La fréquence critique de fusion visuelle en psychopathologie et en psychopharmacologie [Critical flicker fusion frequency in psychopathology and psychopharmacology. Review of the literature]. Acta Psychiatr Belg 82:7-112

Botwinick J, Thompson LW (1966) Premotor and motor components of reaction time. J Exp Psychol 71:9-15

Bouisset S, Matton B (1995) Muscles, posture et mouvement. Base et applications de la méthode électromyographique [Muscles, posture and movement. Basis and applications of the electromyographic method]. Hermann, Paris

Brenner I, Shek PN, Zamecnik J, Shephard RJ (1998) Stress hormones and the immunological responses to heat and exercise. Int J Sports Med 19:130-143

Burle B, Possamaï CA, Vidal F, Bonnet M, Hasbroucq T (2002) Executive control in the Simon effect: an electromyographic and distributional analysis. Psychol Res 66:324-336

Chmura J, Nazar K, Kaciuba-Uscilko H (1994) Choice reaction time during graded exercise in relation to blood lactate and plasma catecholamine threshold. J Sports Med 15:172-176

Chmura J, Krysztofiak H, Ziemba AW, Nazar K, Kaciuba-Uscilko H (1998) Psychomotor performance during prolonged exercise above and below the blood lactate threshold. Eur J Appl Physiol Occup Physiol 77:77-80

Davranche K, Audiffren M (2004) Facilitating effects of exercise on information processing. J Sports Sci 22:419-428

Ghozlan A, Widlöcher D (1993) Ascending-descending threshold difference and internal subjective judgment in CFF measurements of depressed patients before and after clinical improvement. Percept Mot Skills 77:435-439

Halar EM, Hammond MC, Dirks S (1985) Physical activity: its influence on nerve conduction velocity. Arch Phys Med Rehabil 66:605-609

Harikai N, Tomogane K, Miyamoto M, Shimada K, Onodera S, Tashiro S (2003) Dynamic responses to acute heat stress between $34{ }^{\circ} \mathrm{C}$ and $38.5^{\circ} \mathrm{C}$, and characteristics of heat stress response in mice. Biol Pharm Bull 26:701-708
Hasbroucq T, Mouret I, Seal J, Akamatsu M (1995) Finger pairings in two-choice reaction time tasks: Does the between-hands advantage reflect response preparation? J Mot Behav 27:251-262

Hasbroucq T, Possamai CA, Bonnet M, Vidal F (1999) Effect of the irrelevant location of the response signal on choice reaction time: an electromyographic study in humans. Psychophysiology $36: 522-526$

Hasbroucq T, Burle B, Akamatsu M, Vidal F, Possamaï CA (2001) An electromyographic investigation of the effect of stimulusresponse mapping on choice reaction time. Psychophysiology $38: 157-162$

Hasbroucq T, Burle B, Bonnet M, Possamai CA, Vidal F (2002) Dynamique du traitement de l'information sensorimotrice: apport de l'électrophysiologie [The dynamics of information processing: electrophysiological arguments]. Can J Exp Psychol 56:75-97

Hasbroucq T, Tandonnet C, Micallef-Roll J, Blin O, Possamai CA (2003) An electromyographic analysis of the effect of levodopa on the response time of healthy subjects. Psychopharmacology (Berl) 165:313-316

Herskovic JE, Kietzman ML, Sutton S (1986) Visual flicker in depression: response criteria, confidence ratings and response times. Psychol Med 16:187-197

Jianq Y, Rouder JN, Speckman PL (2004) A note on the sampling properties of the Vincentizing (quantile averaging) procedure. J Math Psychol 48:186-195

Lennie P (1998) Single units and visual cortical organization. Perception 27:889-935

McMorris T, Graydon J (2000) The effect of incremental exercise on cognitive performance. Int J Sport Psychol 31:66-81

McMorris T, Myers S, MacGillivary WW, Sexsmith JR, Fallowfield J, Graydon J, Forster D (1999) Exercise, plasma catecholamine concentrations and decision-making performance of soccer players on a soccer-specific test. J Sports Sci 17:667-676

Meijers LM, Teulings JL, Eijkman EG (1976) Model of the electromyographic activity during brief isometric contractions. Biol Cybern 25:7-16

Miller J, van der Ham F, Sanders AF (1995) Overlapping stage models and reaction time additivity: effects of the activation equation. Acta Psychol (Amst) 90:11-28

Motl RW, Dishman RK (2003) Acute leg-cycling exercise attenuates the H-reflex recorded in soleus but not flexor carpi radialis. Muscle Nerve 28:609-614

Motl RW, Dishman RK (2004) Effects of acute exercise on the soleus H-reflex and self-reported anxiety after caffeine ingestion. Physiol Behav 80:577-585

Motl RW, Knowles BD, Dishman RK (2003) Acute bouts of active and passive leg cycling attenuate the amplitude of the soleus $\mathrm{H}$ reflex in humans. Neurosci Lett 347:69-72

Motl RW, O'connor PJ, Dishman RK (2004) Effects of cycling exercise on the soleus H-reflex and state anxiety among men with low or high trait anxiety. Psychophysiology 41:96-105

Possamaï CA, Burle B, Osman A, Hasbroucq T (2002) Partial advance information, number of alternatives, and motor processes: an electromyographic study. Acta Psychol (Amst) 111:125-139

Ratcliff R (1979) Group Reaction time distributions and analysis of distribution statistics. Psychol Bull 86:446-461

Rihet P, Hasbroucq T, Blin O, Possamai CA (1999) Serotonin and human information processing: an electromyographic study of the effects of fluvoxamine on choice reaction time. Neurosci Lett 265:143-146

Samii A, Wassermann EM, Ikoma K, Mercuri B, Hallett M (1996) Characterization of postexercise facilitation and depression of motor evoked potentials to transcranial magnetic stimulation. Neurology 46:1376-1382

Sanders AF (1990) Issues and trends in the debate on discrete vs continuous processing of information. Acta Psychol (Amst) 74:123-167 
Sanders AF (1998) Elements of human performance: reaction processes and attention in human skill. Erlbaum, Mahwah

Sternberg S (1969) The discovery of processing stages: extensions of Donders' method. Acta Psychol (Amst) 30:276-315

Sternberg S (2001) Separate modifiability, mental modules, and the use of pure and composite measures to reveal them. Acta Psychol (Amst) 106:147-246

Tomporowski PD (2003) Effects of acute bouts of exercise on cognition. Acta Psychol (Amst) 112:297-324

Ulrich R, Wing AM (1991) A recruitment theory of force-time relations in the production of brief force pulses: the parallel force unit model. Psychol Rev 98:268-294

Van Boxtel GJ, Geraats LH, Van den Berg-Lenssen MM, Brunia CH (1993) Detection of EMG onset in ERP research. Psychophysiology 30:405-412
Van der Hoeven JH, Lange F (1994) Supernormal muscle fiber conduction velocity during intermittent isometric exercise in human muscle. J Appl Physiol 77:802-806

Van der Molen MW, Bashore TR, Halliday R, Callaway E (1991) Chronopsychophysiology: mental chronometry augmented by psychophysiological time markers. In: Jennings JR, Coles MGH (eds) Handbook of cognitive psychophysiology: central and autonomic nervous system approaches. Wiley, Chichester, UK, pp 9-178

Vincent SB (1912) The function of the vibrossae in the behavior of the white rat. Behavioral Monographs 1:1-181 